\title{
DIFICULDADES MATERNAS NO PROCESSO DE ALEITAMENTO MATERNO DE PREMATUROS EM UMA UTI NEONATAL
}

Sueli Olívia Andreo Serra² Carmen Gracinda Silvan Scochi

Serra SOA, Scochi CGS. Dificuldades maternas no processo de aleitamento materno de prematuros em uma UTI neonatal. Rev Latino-am Enfermagem 2004 julho-agosto; 12(4):597-605.

O estudo objetivou descrever a assistência e as dificuldades maternas no processo do aleitamento materno de prematuros assistidos em uma unidade de terapia intensiva neonatal (UTIN). Para tal, recorreu-se à abordagem qualitativa, obtendo-se os dados através da entrevista estruturada, gravada com cinco mães de bebês prematuros, com peso inferior a 2000g, assistidos no hospital universitário de Cuiabá-MT. Como resultados encontrou-se cinco subtemas: mantendo a produção láctea materna através da ordenha, enfrentando desconforto durante permanência na UTIN, convivendo com as condutas médicas alimentares para prematuros, enfrentando a fragilidade do prematuro e o ambiente da UTIN e precisando de apoio logístico para amamentar. Constatou-se a escassez de intervenções sistematizadas dirigidas ao incentivo do aleitamento materno, durante a hospitalização materna e do prematuro, sendo necessária a capacitação dos profissionais do hospital e a implantação de protocolo de intervenção, contemplando as necessidades e vivências maternas e a articulação das ações intrahospitalares e interinstitucionais.

DESCRITORES: aloitamonto matorno; rocém-nascido; promaturo

\section{MOTHER'S DIFFICULTIES IN BREASTFEEDING PREMATURE} BABIES AT A NEONATAL ICU

This study aimed to describe the care and difficulties mothers face when breastfeeding their premature babies at a neonatal intensive care unit (ICU). Therefore, a qualitative approach was adopted. Data were obtained through structured interviews, which were recorded with five mothers of premature babies under 2,000g who were assisted at the neonatal ICU in Cuiabá-MT, Brazil. The results revealed five subthemes: maintaining milk production by milking, facing discomfort during the stay at the neonatal ICU, living with medical food procedures for premature babies, facing the fragility of the premature baby and the neonatal ICU environment and needing logistic support for breastfeeding. A lack of systematic interventions was observed to stimulate breastfeeding while mothers and their premature babies are in hospital. Hospital professionals need to be trained and intervention protocols have to be implanted, in view of the maternal experiences and needs and the articulation between intrahospital and interinstitutional actions.

DESCRIPTORS: breastfeeding; infant newborn; infant premature

\section{LAS DIFICULTADES MATERNAS EN EL PROCESO DE AMAMANTAMIENTO MATERNO DE PREMATUROS EN UNA UTI NEONATO}

La finalidad del estudio fue describir la asistencia y las dificultades maternas en el proceso de amamantamiento de prematuros. Para tal, recorrimos al abordaje cualitativo, realizada a través de la entrevista estructurada, grabada con cinco madres de ninõs prematuros con peso inferior a 2000 granos acompanãdos en la UTIN en Cuiabá-MT, Brasil. Como resultados verificamos cinco subtemas: mantener la producción de leche materna mediante ordeña, enfrentarse con desconforto durante la estadía en la UTIN, vivir con procedimientos médicos de alimentación para prematuros, enfrentarse con la fragilidad del prematuro y la UTIN y necesitar apoyo logístico para el amamantamiento. Fue observada una falta de intervenciones sistemáticas para estimular el amamantamiento durante la estadía de las madres y sus niños en el hospital. Es necesario capacitar los profesionales hospitalarios y implantar protocolos de intervención, con vistas a las experiencias y necesidades maternas y la articulación entre las acciones intrahospitalarias y interinstitucionales.

PESERIPFORES. Taetancia materna; recién nacido; prematuro

${ }^{1}$ Trabalho extraído da dissertação de mestrado apresentada à Escola de Enfermagem de Ribeirão Preto, da Universidade de São Paulo; ${ }^{2}$ Professor Auxiliar da Faculdade de Enfermagem e Nutrição da Universidade Federal de Mato Grosso, e-mail: sandreos@terra.com.br; ${ }^{3}$ Professor Associado da Escola de Enfermagem de Ribeirão Preto, da Universidade de São Paulo, Centro Colaborador da OMS para o desenvolvimento da pesquisa em enfermagem, e-mail: cscochi@eerp.usp.br 
Estudo realizado na abordagem fenomenológica ${ }^{(3)}$

Na assistência em unidade neonatal de referência terciária, um dos aspectos relevantes no cuidado aos bebês prematuros se refere à alimentação, em virtude de suas limitações gástricas, digestivas e nutricionais. Em decorrência disso, sabemos que muitos são os riscos aos quais os recém-nascidos prematuros de baixo peso ao nascer (BPN) estão sujeitos. Mesmo após a alta hospitalar, essas crianças continuam a ser de alto risco, pois as reinternações são freqüentes durante o primeiro ano de vida, a mortalidade é alta e o crescimento e desenvolvimento em longo prazo sofrem influência de muitos fatores ${ }^{(1)}$, dos quais a alimentação é um deles.

As vantagens do aleitamento materno para prematuros são apresentadas em uma revisão bibliográfica atualizada, sendo destacadas as propriedades nutritivas e imunológicas do leite humano, seu papel na maturação gastrintestinal e formação do vínculo mãe-filho, aumento do desempenho neurocomportamental, menor incidência de infecção, melhor desenvolvimento cognitivo e psicomotor e menor incidência de re-hospitalização. $O$ leite da própria mãe é o mais indicado para o prematuro, contendo, nas primeiras quatro semanas, alta concentração de nitrogênio, proteínas com funções imunológicas, lipídeos totais, ácidos graxos, vitaminas $\mathrm{A}$, $D$ e $E$, cálcio e energia, quando comparado ao leite de mães de neonatos a termo ${ }^{(2)}$.

Todavia, para incentivar o aleitamento materno, torna-se necessário contemplar aspectos relacionados ao prematuro e à mãe-nutriz, devendo-se iniciá-lo precocemente por via gástrica, dar atenção e apoio especial para a manutenção da lactação materna e iniciar o contato pele-a-pele entre mãe e filho e a sucção direta no seio materno, o mais cedo possível. Outro fator a ser observado nas práticas de promoção ao aleitamento materno se refere às necessidades e dificuldades vivenciadas pela mãe.

Sabemos que a mãe do prematuro é uma puérpera que vivencia situações peculiares, diferentes daquela que teve um bebê a termo, enfrentando uma fase de estresse por ter tido uma criança pequena de BPN. Esses bebês necessitam de cuidados especiais dos profissionais de saúde, muitas vezes numa Unidade de Terapia Intensiva Neonatal (UTIN), onde o processo de separação entre mãefilho é previsível. Esses fatos levam a alterações no seu cotidiano, abalando a vivência e dinâmica familiar. revelou que há profundas alterações no modo de ser-como-outro dessas mulheres, pois passam a conviver com sentimentos de revolta, dúvidas, medo, tristeza e angústia, evidenciados por conflitos e dificuldades maternas, que interferem não só na produção e manutenção láctea como, também, na disponibilidade e desejo de amamentar. Somase o fato de que muitas dessas mães de prematuros de baixo peso ao nascer não dispõem de rede de apoio formal (serviços e profissionais de saúde) e informal (familiares, vizinhos e outros), no processo do aleitamento materno.

Os profissionais de saúde que atendem essas mães e bebês, freqüentemente, são responsáveis pelas intervenções assistenciais que envolvem o processo de amamentação. Todavia, essas ações centram-se, quase sempre, nos aspectos biológicos do ato de amamentar; a mulher é vista como um ser cuja função se resume, naquele momento, a produzir leite para alimentar o filho ${ }^{(4)}$. A mãe passa a ter a atenção da equipe, quando essa decide o momento em que o bebê deve sugar no seio materno.

Além disso, os programas de incentivo à amamentação vigentes em nosso país não garantem o sucesso do aleitamento materno, pois trabalham de maneira precária a postura e a capacitação técnica dos profissionais, como também não consideram nas práticas assistenciais, as determinações socioculturais e a perspectiva da mulher inserida nesse processo ${ }^{(3)}$. Acrescese ainda a hospitalização prolongada que, geralmente, os prematuros de BPN necessitam, em decorrência das intercorrências clínicas a que estão expostos, bem como o início tardio da sucção direta no seio materno.

$\mathrm{Na}$ instituição estudada, não dispomos de ações sistematizadas de incentivo ao aleitamento materno, sendo que as mesmas são realizadas de acordo com as características individuais dos profissionais que ali atuam. Não há, também, investigações documentando as dificuldades vivenciadas pelas mães no processo de aleitamento materno na UTIN em questão.

Para que a mãe tenha sucesso na manutenção da lactação, durante a hospitalização de seu bebê, é necessário que se sinta segura e tenha orientação e apoio tanto de sua família quanto dos profissionais de saúde. Esses devem se organizar para que possam fornecer às mães informação, orientação e aconselhamento sobre amamentação como, também, dispor de sistema de acompanhamento no cuidado domiciliar após a alta hospitalar materna. 
Dessa forma, este estudo teve como objetivo descrever as dificuldades maternas no processo do aleitamento materno de prematuros assistidos em uma UTIN.

\section{POPULAÇÃO DE ESTUDO E MÉTODOS}

Trata-se de estudo descritivo exploratório, inserido na abordagem qualitativa. Essa opção considera como sujeito da investigação pessoas pertencentes a determinada condição social, com suas atitudes, aspirações, crenças, significados e valores próprios ${ }^{(5)}$.

O estudo foi desenvolvido na UTIN do Hospital Universitário Júlio Müller (HUJM), Cuiabá-MT, responsável pela assistência a bebês de alto risco. O projeto foi aprovado pelo Comitê de Ética em Pesquisa do HUJM. Trabalhamos com cinco mães procedentes de Cuiabá e cidades do interior do Estado de Mato Grosso, com idade entre 16 e 25 anos, sendo que uma delas teve parto gemelar. Os bebês tinham as seguintes características: $5(83 \%)$ nasceram de parto cesariano e 1 (17\%) de parto normal; idade gestacional variando de 27 semanas e 3 dias a 36 semanas e 2 dias; peso ao nascer variando de 1140 a $1885 \mathrm{~g}$ e duração média da internação de 31,7 dias, variando de 14 a 67 dias.

Dando seqüência, optamos pela entrevista estruturada, com questões abertas e fechadas, orientada por um formulário único, contendo dados de identificação materna e relativos ao aleitamento materno (se tinha experiência em amamentação, se durante a internação recebeu algum tipo de informação sobre o aleitamento materno, cuidados que teve para manter a produção do leite de peito, experiência de amamentação desse filho prematuro, dificuldades enfrentadas no aleitamento materno).

As entrevistas foram realizadas por ocasião da alta hospitalar do bebê, sendo três delas no penúltimo dia de internação na UTIN e duas no último.

Além do registro direto no formulário estruturado, com o termo de consentimento informado, solicitamos assinatura do respectivo termo e autorização para fazer a entrevista gravada em fita magnética e, após, transcrita e digitada na íntegra. Para respeitar o direito ao anonimato, as mães foram identificadas por um codinome relacionado ao nome de flores. A duração das entrevistas foi, em média, de trinta minutos. Ao final, orientamos as mães sobre as dúvidas expressas acerca dos cuidados com o bebê e com a amamentação.

As informações foram organizadas e ordenadas em arquivos individuais. Após a ordenação, iniciamos a leitura ampla e repetida das entrevistas, assim íamos ordenando as falas e agrupando-as por semelhanças entre si, dessa forma, algumas foram vinculadas a outras e com isso passaram por um processo de redução $0^{(5)}$, o que possibilitou agrupar as falas em temas por sua semelhança, constituindo-se em subtemas e, finalmente, a definição de temas mais abrangentes, que englobaram os temas menores. Assim, chegamos ao tema objeto deste estudo, as dificuldades maternas no processo do aleitamento materno, em uma UTIN.

\section{RESULTADOS E DISCUSSÃO}

Buscamos conhecer, através das falas das entrevistadas, as dificuldades por elas vivenciadas no processo do aleitamento materno. Esse tema envolveu cinco subtemas: mantendo a produção láctea materna através da ordenha, enfrentando desconforto durante permanência na UTIN, convivendo com as condutas médicas alimentares para prematuros, enfrentando a fragilidade do prematuro e o ambiente da UTIN, precisando de apoio logístico para amamentar.

Mantendo a produção láctea materna através da ordenha

Estimular a lactação através da ordenha mamária foi uma orientação que todas as entrevistadas referiram ter recebido dos profissionais da Obstetrícia ou da UTIN do HUJM.

(...) aí ela falou que era pra cuidar, pra tirar, pra esvaziar mesmo... (Margarida).

Falaram pra ordenhar (Gardênia).

(...) só falaram assim, porque tava empedrando, que era pra eu tirar...(Camélia).

Ao limitar a assistência dirigida a essas mãenutrizes, quando se faz apenas orientações verbais, de certa forma os profissionais acabam repassando para a mãe a responsabilidade de produzir leite e manter a lactação. Nesse sentido, questiona-se porque não fazer uma ordenha junto com a puérpera, tranqüilizando-a e, ao mesmo tempo, orientando e dando apoio.

A sucção do seio materno constitui fator 
importante para a manutenção da lactação $0^{(6)}$. Todavia, as mães de muitos recém-nascidos pré-termo não têm essa possibilidade devido à imaturidade e condição clínica do filho, além do estresse que vivenciam.

Em casos em que a amamentação não é iniciada nas primeiras horas após o parto, a ordenha da mama é recomendada ${ }^{(6)}$, pois serve para estimular a produção láctea e evitar o ingurgitamento mamário. Além disso, ao fornecer o leite para o filho, na UTIN, a mãe se sente importante no processo de recuperação da saúde de seu filho, fortalecendo assim o vínculo afetivo mãe-filho e o sentimento de se sentir parte do processo terapêutico do bebê, estimulando-a a proceder à ordenha mais vezes ${ }^{(7)}$.

A ordenha do leite materno para os filhos tem sido importante para estabelecer o vínculo, pois as mães sentem-se satisfeitas por alimentá-los, poder dar-Ihes algo que é seu, fazendo-as ter a impressão de estarem próximas de uma situação de normalidade, o que lhes dá a oportunidade de se julgarem menos excluídas do processo assistencial do bebê e menos inseguras ${ }^{(7-8)}$.

Para a manutenção da lactação, outro aspecto abordado nas orientações refere-se à freqüência da ordenha. A equipe de enfermagem orientou algumas das mães entrevistadas que o intervalo das ordenhas deveria ser de três horas.

De três em três horas (...) tirava às vezes de três em três horas (Violeta).

(...) falaram (enfermagem) pra mim que de três em três horas taria bom, daí eu tiro de três em três horas... (Margarida).

Em casos como esses em que os bebês não puderam ficar com as mães, recomenda-se que a mãe deve retirar o leite logo após o parto, se possível nas primeiras 12 horas, durante 15 a 20 minutos e pelo menos sete vezes em 24 horas $^{(6)}$. Essas recomendações muitas vezes esbarram nas dificuldades que a mãe do prematuro enfrenta para manter a produção de leite ao permanecer com o filho o dia todo, ou parte desse, na UTIN, durante vários dias ou várias semanas. Percebemos que, freqüentemente, os profissionais da unidade neonatal não propiciam ou estimulam que a mãe realize a ordenha mamária, enquanto permanece junto ao filho, fato que aponta um elemento para ser trabalhado na capacitação dos profissionais de saúde.

A falta de um local para a ordenha mamária é dificuldade relatada por Violeta, para que as mães possam realizá-la de forma privativa, sem se exporem fisicamente às pessoas estranhas, principalmente do sexo masculino, o que está sendo previsto no processo de reforma física do hospital.

Às vezes tirava (leite), às vezes não, porque aqui tem um certo movimento fica ruim, (...) quer dizer não tinha espaço, aí tem residente, tem homem também trabalhando na área (pessoal da manutenção) (Violeta).

Enfrentando desconforto durante permanência na UTIN

As entrevistadas verbalizaram dificuldades relacionadas à infra-estrutura oferecida pela instituição para permanecer com o filho na UTIN. Fizeram referência à necessidade de se alimentar bem para continuar produzindo leite, um problema enfrentado quando permaneciam na UTIN durante todo o dia, sem reforço na alimentação nos períodos entre as refeições.

(...) porque você não pode trazer nenhum tipo de alimentação (...) eu só almoço e janto... (Violeta).

(...) como não pode entrar com nada né (...) daí a alimentação já fica um pouco mais diminuída (Margarida).

Durante a gravidez e o alactamento, a mãe tem maiores necessidades nutricionais para sua própria saúde e para saúde de seu bebê. A dieta materna pode afetar a produção de leite, embora a relação mútua entre dieta/ volume de leite não seja ainda bem entendida, é importante assegurar ingesta nutritiva e hídrica suficiente para atender as necessidades da mãe-nutriz.

A rotina do HUJM não permite que visitantes entrem no hospital com qualquer tipo de alimento. Para os acompanhantes são fornecidas duas refeições por dia, almoço e jantar; para as nutrizes que acompanham os filhos na unidade pediátrica é fornecido ainda o café da manhã.

Aos funcionários do HUJM é fornecido um lanche no meio do período de trabalho, no refeitório do hospital. Por alguns anos, esse lanche era estendido às mães lactantes que acompanhavam seus filhos na UTIN, sendo servido no período da manhã e da tarde. Oferecia-se, ainda, uma garrafa térmica com suco exclusivo para as mães, a qual era substituída duas vezes por dia, de manhã e à tarde. Contudo, atualmente, o lanche só é oferecido aos servidores, médicos residentes e acadêmicos, durante seu turno de trabalho/plantão.

Essa norma é de conhecimento de uma das entrevistadas, sinalizando que o oferecimento complementar do lanche, duas vezes ao dia, para as mães atenderia às suas necessidades nutritivas, possibilitando a maior permanência junto ao filho na UTIN. 
O lanche que vem é para as enfermeiras né, (...) mandam tudo contadinho pra elas (enfermagem). Então se vier (lanche para as mães) é melhor, ajuda... (Violeta).

Nesse sentido, torna-se necessário que as instituições atentem para as necessidades maternas ou do acompanhante ao inseri-los na dinâmica cotidiana da instituição. A presença da mãe ou do pai em tempo integral no hospital, acompanhando o filho internado, é um direito garantido pelo Estatuto da Criança e do Adolescente, Lei № 8069 , de 16 de julho de $1990^{(9)}$.

Para atender essa Lei, a UTIN necessita, ainda, dispor de espaço e acomodações confortáveis e em número correspondente ao de leitos ali existentes.

A UTIN deve dispor de área destinada à ordenha $e$ amamentação ${ }^{(10)}$ e espaço apropriado também deve ser planejado, para a orientação da família dentro da própria UTIN.

O problema é a gente ficar sentada (...) muito tempo a gente não agüenta né., Não tem espaço (...) é ruim para as mães, o desconforto (...) não tem acomodação (Violeta).

Para atender as recomendações é indispensável que as instituições assegurem infra-estrutura mínima e acomodações para que a mãe permaneça junto ao filho, na perspectiva de assistência mais integral e humanizada.

Em um estudo sobre a inserção do acompanhante em unidades de internação pediátrica no Distrito Federal, a autora observou que, apesar das modificações ocorridas com a institucionalização do acompanhante, os problemas continuam sem solução, tais como: o espaço dentro das enfermarias cada vez menor, acomodações inadequadas, cadeiras desconfortáveis, banheiros distantes e, em alguns locais, inexistência de refeitório, entre outros ${ }^{(11)}$. Os resultados dessa investigação retratam, de certa forma, a realidade de muitas instituições nacionais. No HUJM também são vivenciadas essas limitações, sendo inclusive verbalizadas pelas entrevistadas.

Assim, acreditamos ser necessário fazer com que a presença das mães se transforme em parceria entre essa e a equipe de saúde, visando o bem-estar do bebê sem, no entanto, permitir que a mãe passe por privações e desconforto no processo de acompanhar seu filho na UTIN.

Convivendo com as condutas médicas alimentares para prematuros

O processo inicial de amamentação é dificultado quando acontece de o bebê ainda estar recebendo parte da alimentação por sonda orogástrica e parte por mamadeira.

(...) o primeiro (Elias) não quis pegar muito bem (...) é por causa da sonda né... (Camélia).

No início da amamentação, a mãe do prematuro enfrenta dificuldades também decorrentes não só das limitações fisiológicas do filho, mas também das rotinas hospitalares que retardam o início da sucção direta no seio materno e a condicionam ao oferecimento da mamadeira, conforme mostram as falas, a seguir.

(...) quando ela conseguisse mamar tudo isso na chuquinha e não cansar, daí vai começar a dar só o peito que ela vai estar mais forte (Margarida).

Ele nega um pouco por causa da chuquinha né, porque eles vão pra chuquinha primeiro... (Violeta).

Na rotina da UTIN do HUJM se faz a transição da alimentação por sonda orogástrica para chuca antes de sugar no seio materno. Consta da norma institucional que o recém-nascido deve receber leite materno ordenhado na mamadeira, quando estiver com peso entre $1500 \mathrm{e}$ $1800 \mathrm{~g}$ e/ou idade gestacional de 32 a 35 semanas, com boa sucção e deglutição e, para sugar no seio materno, o bebê deve ter peso superior a $1800 \mathrm{~g} \mathrm{e} / \mathrm{ou}$ idade superior a 35 semanas, ter boa aptidão para sugar e deglutir.

Esse tipo de rotina acaba retardando o início da sucção no seio materno. Nesse sentido, a Iniciativa Hospital Amigo da Criança recomenda o método do copinho (vidro ou plástico sem rebordo ou bico), na transição da alimentação láctea por sonda orogástrica para a alimentação com sucção direta no seio materno ${ }^{(6)}$.

Muitas estratégias de alimentação têm sido desenvolvidas para minimizar o "trabalho de sucção" do prematuro, na suposição de que ele tenha uma sucção fraca. $\mathrm{Na}$ realidade, o prematuro tem uma habilidade limitada no aumento ou redução da pressão na sucção em relação ao fluxo de leite ${ }^{(12)}$.

O relato de Violeta reforça o posicionamento de alguns autores, ao afirmarem que um importante fator que pode influenciar negativamente no sucesso da amamentação é o uso prolongado de mamadeiras e bicos de borracha pelo bebê prematuro, que terá maior dificuldade em aceitar o seio materno, visto que o estímulo e a dinâmica da sucção são diferentes nos dois tipos de bico ${ }^{(13-14)}$; isso pode confundir o bebê e ele poderá optar por aquele que the for oferecido com mais freqüência.

Outro aspecto importante a ser observado refere- 
se ao preceito que tem fundamentado a prática alimentar em muitos serviços neonatais - que a sucção na mamadeira é menos desgastante para o prematuro que a sucção no seio materno, sendo, portanto, utilizado como etapa de transição para a amamentação materna.

Nesse sentido, um estudo realizado no Hospital das Clínicas de Ribeirão Preto comparou os efeitos da sucção na mamadeira e no seio materno em seis recémnascidos prematuros e de muito baixo peso. A autora constatou importantes alterações na saturação do oxigênio $\left(\mathrm{SpO}_{2}\right)$ e no surgimento de sinais de alarme, como batimento de aletas nasais, alterações da coloração da pele e do tônus muscular. Durante as sessões de sucção na mamadeira, as situações de risco decorrentes da queda de $\mathrm{SpO}_{2}$ para níveis inferiores a 92\% não ocorreram em quantidade significativamente maior, pois as sessões foram interrompidas, em freqüências estatisticamente maiores que as sessões de sucção no seio materno. Contudo, a análise da dimensão do risco em profundidade mostrou diferenças importantes, com maior duração no tempo de hipoxemia e valores de $\mathrm{SpO}_{2}$ menores, caracterizando estresse fisiológico nos prematuros pequenos, durante a sucção na mamadeira, quando comparadas à sucção no seio materno ${ }^{(15)}$.

Face aos resultados desses estudos, consideramos oportuno repensar as rotinas do HUJM, no sentido de possibilitar o contato entre mãe e filho, início precoce da sucção no seio materno e implantar outras estratégias, visando a manutenção da lactação, pois, além de fazer a transição com o uso da chuca, a amamentação materna é tardia e pouco freqüente.

Faz dois dias (estava no segundo dia e foi de alta no dia seguinte), ela começou ontem de manhã (...) dei duas mamadas...(Margarida).

Na rotina da UTIN, normalmente o bebê é liberado para sugar uma vez por cinco minutos no primeiro dia, aumentando para duas vezes no segundo e ficando liberado para sugar livremente a partir do terceiro dia de prescrição médica.

Enfrentando a fragilidade do prematuro e o ambiente da UTIN

Ainda quanto às dificuldades encontradas pelas mães no processo de amamentação, algumas mães referiram certo grau de dificuldade devido ao bebê ser pequeno.
(...) eles são muito delicados, pequenos né... (Violeta).

Eles são tão pequenos que eu tenho horror de segurar (...) A maior dificuldade foi de pegar, por ser muito pequena né (Gardênia).

Em casos de mães de prematuros, principalmente primíparas, recomenda-se que a equipe de saúde favoreça o contato da mãe primeiramente com outros bebês prematuros, com características físicas similares ao seu, na intenção de desfazer a imagem do bebê robusto imaginado ${ }^{(16)}$.

Os profissionais de saúde que atuam na UTIN devem ser sensíveis a esses sentimentos vivenciados pelas mães e implantar estratégias que propiciem às mães expressar seus medos e anseios, inserindo-as gradualmente no cuidado, visando desenvolver habilidades e o vínculo afetivo, conforme a assistência realizada no Hospital das Clínicas de Ribeirão Preto ${ }^{(7)}$.

Outro aspecto apontado por Açucena refere-se ao ambiente da UTIN, cheio de aparelhos e equipamentos, às vezes barulhentos e complexos.

Eu nunca tinha entrado numa UTI... Nossa pra mim era uma realidade muito distante... (Açucena).

Embora os pais tenham acesso permitido na UTIN, eles não foram preparados para um parto prematuro e muito menos para ver seu filho numa incubadora, rodeado de equipamentos estranhos, fios e vários tubos. Assim, eles têm que enfrentar a complexidade do ambiente e a rotina agitada da unidade que, somadas à preocupação com a saúde de seu bebê, acabam gerando ansiedade e medo.

É necessária uma rede de apoio informal, que envolva a ajuda de parentes, de amigos e da comunidade, e de apoio formal, proveniente dos serviços profissionais, que vão auxiliar os pais no processo de experienciar a internação do filho prematuro em uma UTIN ${ }^{(7)}$.

Esse tipo de trabalho é realizado no Hospital das Clínicas de São Paulo, desde 1984, com a criação do GRUPAR - Grupo de Pais de Prematuros de Alto Risco, que desenvolve trabalho de atendimento multiprofissional aos pais, por meio de reuniões realizadas duas vezes por semana, visando transmitir informações sobre o estado clínico do bebê, a terapêutica, o prognóstico e exames complementares, bem como esclarecer as dúvidas trazidas pelos pais, suas ansiedades, expectativas e medos ${ }^{(8)}$.

Trabalho semelhante é desenvolvido no Hospital das Clínicas de Ribeirão Preto, onde os pais de bebês prematuros participam de um grupo de apoio, juntamente com outros pais que tiveram experiências anteriores semelhantes. As reuniões são realizadas uma vez por 
semana, nas quais são fornecidas informações acerca da condição clínica e terapêutica do bebê. Os pais têm oportunidade de expressar seus sentimentos decorrentes de ter um bebê de risco hospitalizado e também são esclarecidas suas dúvidas, oportunizando a troca de experiências entre eles ${ }^{(7)}$.

Nesse processo é necessário cuidar dos pais para que tenham condições de reelaborarem o momento vivido e assim se organizarem para atender as necessidades do filho na UTIN. Uma das atribuições da enfermagem deve ser a de apoiar a competência dos pais para o cuidado do seu bebê na UTIN, a fim de torná-los parceiros nos cuidados aos recém-nascidos ${ }^{(3)}$.

Precisando de apoio logístico para amamentar

Um dos aspectos que precisa de (re)organização dos pais relaciona-se à necessidade de ir à UTIN diariamente. Pode parecer simples, mas acaba se complicando quando eles não residem na cidade em que o bebê está hospitalizado, não dispõem de recursos financeiros para o transporte até o hospital, têm que conviver com a longa duração da internação do filho ou quando não têm com quem deixar os outros filhos ainda pequenos.

Para aqueles que não moram em Cuiabá, as dificuldades estão na hospedagem e na locomoção em uma cidade desconhecida.

Aqui eu tô no hotel, e pra mim não ficar sozinha minha mãe veio comigo (...) vinha de táxi porque eu tava operada, e eu tinha medo de pegar o ônibus e me perder, porque eu não conheço nada aqui (Margarida).

Só uma, porque de onde a gente tá parando (hospedada) pra vim pra cá precisa pegar táxi, pra ir embora táxi de novo... É longe e de ônibus é ruim pra mim (Gardênia).

A mãe de Margarida veio acompanhando-a de sua cidade do interior do Estado. Ambas ficaram hospedadas próximo ao HUJM, mas enquanto Margarida tinha acesso à UTIN durante todo dia e à noite, até às 21 horas, sua mãe só podia entrar por poucos minutos no período da tarde e, ainda assim, permanecer no corredor do lado de fora da UTIN, vendo filha e neta pelo visor. O restante do dia ficava no pátio do hospital, almoçando num pequeno restaurante em frente ao hospital. Apesar disso, Margarida não referiu que isso era uma dificuldade, mas sim que todo esse processo fazia parte da maternidade de ambas.

A visão idealizadora de uma maternidade de doações e sacrifícios cria a mãe masoquista, em que todo sofrimento que dela possam advir deve ser bem tolerado, já que é inerente à sua função de mãe ${ }^{(17)}$. No período estudado, a visita das avós não era permitida, mas atualmente, as normas da UTIN já autorizam a entrada de avós apenas às terças e quintas-feiras das 14 às 15 horas, o que ainda merece revisão. Destacamos tal transformação na assistência, pois as avós são importante fonte informal de apoio aos pais, principalmente à mãe. No caso da mãe de Margarida, a liberação de sua visita, mesmo com hora determinada, teria efeito de uma recompensa ao seu esforço, apoio e preocupação com a filha e a neta, durante esse período sensível.

Gardênia também não mora em Cuiabá, veio para a capital alguns dias após o nascimento da filha prematura, acompanhada do marido, e ambos permaneceram hospedados na casa da prima dele que reside em um bairro distante do hospital, cerca de quarenta minutos de ônibus.

Para Camélia, residente em Cuiabá, que tem outros dois filhos menores e limitados recursos financeiros, as dificuldades a serem vencidas são muitas.

Tudo (é difícil) (...) tem que pegar dois ônibus pra vir pra cá. Pra arrumar o dinheiro pra vir todo dia é complicado (...) Meu maior problema é deixar os meus filhos (Camélia).

Por outro lado, Violeta e Açucena referiram que não tiveram dificuldades para vir ao hospital.

(...) Mas porque tem o carro né, então meu marido me traz (Violeta)

Não tenho dificuldade nenhuma, porque meu tio me traz, pouquíssimas vezes eu vim de ônibus (Açucena).

Açucena estava desempregada, a tia a ajudava financeiramente e ainda recebia alguns vales transporte do Serviço Social do HUJM, que custeava sua vinda de ônibus durante alguns dias.

Minha tia (que fornece dinheiro para o ônibus), às vezes eu também recebo passe (vale transporte) da assistente social, mas é pouco (...) dura em média dez dias (Açucena).

O Serviço Social do HUJM distribui, entre as mães que necessitam de auxílio para o transporte de casa até o hospital, a quantia de cinqüenta vales transporte mensais. Essa quantia é fixa e independe do número de mães inscritas para o auxílio. Contudo, essa informação nem sempre chega a todas as mães, caso ela não verbalize dificuldades financeiras para ir e vir.

Para que a promoção do aleitamento materno tenha sucesso, são necessários vários tipos de apoio e 
esses vão depender das características da clientela, suas condições econômicas e socioculturais. No caso de algumas mães, não só aquelas que fizeram parte deste estudo, sanar o problema de transporte para ir e vir de casa ao hospital era o apoio que necessitavam para que pudessem permanecer junto ao filho na UTIN e promover o aleitamento materno.

\section{CONSIDERAÇÕES GERAIS}

Neste estudo ficou conhecido, através das falas das entrevistadas, que as dificuldades maternas no processo do aleitamento materno decorrem da falta de infra-estrutura para amamentar e ordenhar o leite materno, bem como dos recursos que dispõem para transporte e cuidado dos outros filhos.

Face aos resultados apresentados, consideramos oportuno repensar a prática alimentar utilizada na UTIN do HUJM, no sentido de transformar suas rotinas para possibilitar o contato entre mãe e filho, viabilizar o início precoce da sucção no seio materno e implantar outras estratégias visando a manutenção da lactação. A discussão dessas práticas se faz necessária assim como a implantação de protocolos assistenciais dirigidos ao incentivo e à promoção do aleitamento materno.

Conforme já constatado anteriormente, a assistência na UTIN é centrada no corpo biológico e as ações relacionadas ao aleitamento materno não estão sistematizadas, ficando na dependência das

\section{REFERÊNCIAS BIBLIOGRÁFICAS}

1. Lucena L, Lima RT, Marino WT. O baixo peso ao nascer ainda é um problema de saúde pública no Brasil. Rev Paul Pediatria 1993; 16(1):15-27.

2. Nascimento MBR, Issler $\mathrm{H}$. Breastfeeding: making the difference in the development, health and nutrition of term and preterm newborns. Rev Hosp Clín Fac Méd S Paulo 2003; 58(1):49-60.

3. Gomes MMF. As repercussões familiares da hospitalização do recém-nascido na UTI Neonatal: construindo possibilidades de cuidado. [doutorado]. São Paulo (SP): Departamento de Enfermagem/UNIFESP; 1999.

4. Javorski M. Os significados do aleitamento materno para mães de prematuros em cuidado canguru. [dissertação]. Ribeirão Preto (SP): Escola de Enfermagem/USP; 1997.

5. Minayo MCS. O desafio do conhecimento: pesquisa qualitativa em saúde. $5^{\underline{a}}$ ed. São Paulo (SP): Hucitec-Abrasco; 1998.

6. Ministério da Saúde (BR). Manejo e Promoção do Aleitamento Materno. Programa Nacional de Incentivo ao Aleitamento Materno/Grupo de Defesa da Saúde da Criança. Brasília (DF): Ministério da Saúde; 1993. características pessoais do profissional, ocorrendo também o repasse de informações fragmentadas às mães, carecendo muitas vezes de fundamentação científica atualizada. Acreditamos que isso se deva ao fato da UTIN não dispor de norma escrita dirigida ao incentivo do aleitamento materno e os profissionais que ali atuam não serem sistematicamente treinados para dar proteção, promoção e apoio ao aleitamento materno.

Nesse sentido, estamos envidando esforços para implementar estratégias assistenciais, por meio do estabelecimento de um protocolo de intervenção que contemple a promoção do aleitamento materno, envolvendo não só a equipe da UTIN, mas também todos os profissionais que atendem as gestantes, as puérperas e os recém-nascidos no seguimento ambulatorial do HUJM.

Esta pesquisa apontou vários elementos que podem compor o protocolo de intervenção nesta realidade descrita, que orientará, dentre outras ações, aquelas relacionadas à capacitação dos profissionais de enfermagem da instituição estudada.

Outro aspecto a ser contemplado nesse processo envolve a participação da família e comunidades nos serviços de apoio voltados para a mãe, atuando de forma constante, ligada ao serviço social do HUJM, tanto nas atividades de apoio financeiro, cuidado com outros filhos, afazeres domésticos, como também, no apoio emocional à mãe.

Esta proposta carece de implementação e avaliação no HUJM, o que pretendemos realizar em estudo futuro.

7. Scochi CGS, Kokuday MLP, Riul MJS, Rossanez LSS, Fonseca LMM, Leite AM. Incentivando o vínculo em situação de prematuridade: as intervenções de enfermagem no Hospital das Clínicas de Ribeirão Preto. Rev Latino-am Enfermagem 2003 julho-agosto; 11(4):539-43.

8. Gomes ALH, Quayle J, Neder M, Leone CR, Zugaib M. Mãebebê pré-termo: as especificidades de um vínculo e suas implicações para a intervenção multiprofissional. Rev Ginecol \& Obstet 1997; 8(4):205-8.

9. Setor de Pastoral Social da CNBB (BR). Estatuto da criança e do adolescente. Lei 8.069 de 13 de julho de 1990. Art.12. Brasília;1990. p.10.

10. Comitê de Neonatologia da Sociedade de Pediatria de São Paulo (BR). Padronização de UTI neonatal - critérios mínimos. Rev Paul Pediatria 1995; 13(4):143-6.

11. Cristo RC. A inserção do acompanhante em unidades de internação pediátrica no Distrito Federal-DF. [dissertação]. Ribeirão Preto (SP): Escola de Enfermagem/USP; 1999.

12. Matthew OP. Science of bottle feeding. J Pediatr 1991; 119:511-9.

13. Meier P, Anderson GC. Responses of smal preterm infants to bottle and breast-feeding. MCN Am J Matern Child Nurs $1987 ; 12(2): 97-105$. 
14. Vinha VHP, Pela NTR, Scochi CGS, Shimo AKK, Gameiro C. Manutenção da lactação da mãe do prematuro - uma proposta de cuidados. Femina 1988; 16(11):994-7.

15. Silva MHA. Alimentação de bebês prematuros e de muito baixo peso: efeitos da sucção à mamadeira e ao seio materno. [dissertação]. Ribeirão Preto (SP): Escola de Enfermagem/USP; 1999.

16. Rego JD. O aleitamento materno - vantagens e obstáculos reais à amamentação: estado atual e tendências futuras. J Bras Med 1986; 50(3):13-23.

17. Badinter E. Um amor conquistado: o mito do amor materno. 8르 ed. Rio de Janeiro (RJ): Nova Fronteira; 1985. 